\title{
Estudio de rendimiento energético de bioceldas solares
}

\section{Study of the energy performance of solar biocells}

DOI: $10.46932 / \mathrm{sfjdv} 3 \mathrm{n} 1-025$

Received in: Dec 30st, 2021

Accepted in: Jan 1th, 2022

\author{
Ruben Téllez Hernández \\ MC (Maestría en Ciencias) y Tiempo Completo asociado A \\ Universidad Tecnológica de Tecamachalco, Puebla
}

Avenida, Universidad Tecnológica 1, Barrio la Villita, 75483 Tecamachalco, Pue.

E-mail: ruben.tehe@hotmail.com

Fermín Tenorio Cruz

Profesor Tiempo Completo asociado B y MER (Maestría en Energías Renovables)

Universidad Tecnológica de Tecamachalco, Puebla

Avenida, Universidad Tecnológica 1, Barrio la Villita, 75483 Tecamachalco, Pue.

E-mail: ftenorioc@yahoo.com

\section{Erik Juarez Cortes}

Profesor Tiempo Completo asociado B y MER (Maestría en Energías Renovables)

Universidad Tecnológica de Tecamachalco, Puebla

Avenida, Universidad Tecnológica 1, Barrio la Villita, 75483 Tecamachalco, Pue.

E-mail: ek_24@hotmail.com

\author{
Alberto Vera Camacho \\ Profesor Tiempo Completo asociado C y MER (Maestría en Energías Renovables) \\ Universidad Tecnológica de Tecamachalco, Puebla \\ Avenida, Universidad Tecnológica 1, Barrio la Villita, 75483 Tecamachalco, Pue. \\ E-mail: albertovera16_06@hotmail.com
}

\begin{abstract}
RESUMEN
La búsqueda de fuentes de energía es uno de los retos más grandes de la ciencia e ingeniería la, cual investiga para evitar de destruir nuestro planeta utilizando energéticos que contaminen el medio ambiente. Una de las más comunes es la energía solar, basada en células fotovoltaicas que utilizan las cargas opuestas producidas por la energía lumínica para crear un campo eléctrico y, con él, generar corriente. En breve, el consumo de esta fuente de energía ha ido aumentando a nivel mundial, y la investigación de un modo de potenciar el método no ha parado ni un solo momento, así en la naturaleza quienes más dominan en el uso la luz del sol para obtener energía son las plantas y algunas bacterias, por lo que si no podemos ser mejores que ellas tan solo es mejor imitarlas y aprovechar sus recursos como fuentes de modelado en el aprovechamiento de esa energía, y en lo posterior aprovechar esa energía solar. En el futuro el mejor aprovechamiento de la energía solar y mayor eficiencia energética en el uso de bioceldas solares, es el objetivo de este estudio, aprovechar la energía lumínica y convertirla en útil energía eléctrica y aprovechar al máximo ese potencial para cubrir nuestras necesidades de energía mundial.
\end{abstract}

Palabras clave: Energéticos, células, fotovoltaicas, cargas. 


\begin{abstract}
The search for energy sources is one of the greatest challenges of science and engineering, which researches to avoid destroying our planet by using energy sources that pollute the environment. One of the most common is solar energy, based on photovoltaic cells that use the opposite charges produced by light energy to create an electric field and, with it, generate current. In short, the consumption of this energy source has been increasing worldwide, and research into a way to enhance the method has not stopped for a single moment, so in nature those who most dominate the use of sunlight for energy are plants and some bacteria, so if we can not be better than them it is only better to imitate them and take advantage of their resources as sources of modeling in the use of that energy, and subsequently take advantage of that solar energy. In the future the best use of solar energy and greater energy efficiency in the use of solar biocells, is the objective of this study, to take advantage of light energy and convert it into useful electrical energy and make the most of this potential to meet our global energy needs.
\end{abstract}

Keywords: Energetics, cells, photovoltaic, loads, solar cells, photovoltaic, solar cells.

\title{
1 INTRODUCCIÓN
}

Una celda de combustible biológica (CCB) o una celda de combustible microbiana (CCM) es un dispositivo en el cual la energía química de un compuesto, normalmente glucosa, acetato u otras formas de materia orgánica disuelta, se convierte a energía eléctrica por medio de la acción bacteriana. Geobacter

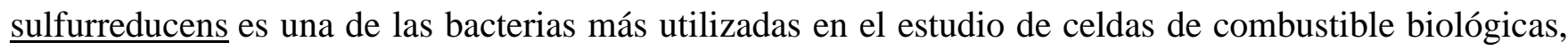
por su alta eficiencia de conversión energética. En las aplicaciones probables para estas celdas se encuentra el tratamiento de efluentes con alto contenido de materia orgánica y la generación de corriente eléctrica en sedimentos marinos. Debido a que estas técnicas están primordialmente en su etapa de desarrollo experimental y piloto las potencias obtenidas son todavía bajas y no hay actualmente aplicaciones comerciales ya disponibles, aunque el gran desarrollo en los últimos años de investigación hace posible ver un futuro prominente a mediano plazo.

Otra investigación nos dice que un compuesto orgánico es aquél que está formado por átomos de carbono e hidrógeno $(\mathrm{C}, \mathrm{H})$. Estos compuestos pueden también contener átomos de nitrógeno, oxígeno $(\mathrm{N}, \mathrm{O})$, azufre $(\mathrm{S})$, entre otros; los átomos de carbono se unen por enlaces covalentes que pueden ser de dos distintos tipos, sigma y pi $(\sigma, \pi)$. Los primeros son enlaces sencillos, es decir, solo intervienen un par de electrones, mientras que en los enlaces pi pueden existir un enlace doble o uno triple; ambos enlaces $(\sigma \mathrm{y} \pi)$ presentan diferentes propiedades tanto estructurales como electrónicas. Un ejemplo se encuentra en la deslocalización de los electrones en la estructura conjugada y que confiere al compuesto propiedades opto-electrónicas muy interesantes (figura 1). Los compuestos que poseen únicamente enlaces sigma son por lo general incoloros, mientras los que tienen enlaces pi son usualmente coloridos. Cuando además los dobles enlaces se encuentran conjugados, es decir, existe una sucesión entre un enlace sencillo y uno doble, los compuestos son muy coloridos (como es el caso de muchos productos naturales). Un ejemplo 
es el licopeno, responsable del color rojo del jitomate, que presenta 11 dobles enlaces $\pi$ conjugados. Los compuestos que contienen enlaces pi conjugados pueden ser de bajo peso molecular (o polímeros) y muestran propiedades de gran interés en el área de los materiales fotónicos. El diseño y síntesis de estos materiales se realiza en laboratorios de química.

Figura 1. Estructura química general de moléculas dipolares orgánicas conjugadas.

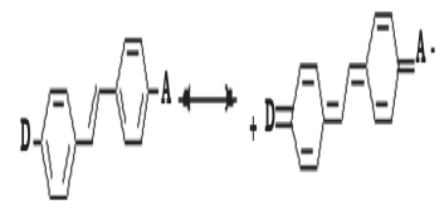

\subsection{MACROMOLÉCULAS EN CELDAS SOLARES}

La conversión de energía solar en energía química es uno de los procesos fundamentales para el origen y la permanencia de la vida en este planeta; en este proceso ciertas moléculas como las proteínas y las porfirinas han jugado un papel importante. Las porfirinas son una familia de sustancias de origen orgánico que están formadas por 4 anillos aromáticos de cinco miembros que contienen nitrógeno (anillo de pirrol). En particular, la clorofila (una porfirina) atrapa la luz solar para sintetizar moléculas que almacenan la energía química para ser distribuida en los diferentes procesos biológicos. En simultáneo, se han explorado diferentes estrategias como el diseño racional de nuevos péptidos (conjunto de aminoácidos). Los péptidos son portadores de electrones, con estructura similar a la de las proteínas nativas, capaces de realizar esta función dentro de los seres vivos. También se han usado péptidos como espaciadores entre los sustratos de conducción en sistemas de celdas solares DSSC para aumentar la capacidad de conversión de energía fotoeléctrica producida. Por otra parte, moléculas de este tipo permiten el control morfológico de los ensamblajes de óxidos metálicos usados en opto electrónica como óxidos de zinc y de titanio; entre otras funciones, ayudan a mejorar el contacto con los electrodos e incrementar la colección de cargas eléctricas. Ejemplo de lo anterior es la producción de redes de nanoespirales de óxido de titanio (TiO2) en el diseño de DSSC, usando dipéptidos estructurados como molde de la estructura tridimensional, lo que produce nano estructuras de $\mathrm{TiO} 2$ de características altamente homogéneas a lo largo de la superficie. Lo de homogéneas significa, por ejemplo, que mejoran el contacto con los electrodos al disminuir las irregularidades a nivel nanométrico. En una aproximación más cercana a lo observado en los sistemas de captura de energía solar naturales, se han usado péptidos capaces de unir porfirinas para producir nanoestructuras que pueden ser usadas como antenas colectoras en el diseño de nuevas celdas solares. No obstante, la limitante más importante para el uso de péptidos o proteínas como portadores de electrones es el daño que reciben por la exposición continua a la radiación. Por fortuna, esta aparente limitante genera un amplio campo de investigación en el uso de aminoácidos y péptidos no 
naturales que ha sido poco explorado.

\subsection{COMPUESTOS ORGÁNICOS DEPOSITADOS EN PELÍCULAS DELGADAS}

Una de las ventajas que tienen los compuestos orgánicos es la versatilidad con la que se pueden realizar modificaciones estructurales que permiten modular las propiedades deseadas. Lo anterior posibilita, por ejemplo, de una manera relativamente fácil y rápida la fabricación de películas de estado sólido con grosores comparables al de un cabello humano (películas gruesas), o bien, cerca de mil veces más delgadas (películas delgadas). Las películas se pueden depositar a temperatura ambiente sobre una gran variedad de sustratos, lo que es fundamental para la fabricación de los dispositivos fotónicos y optoelectrónicos plásticos como las celdas OPVs (organic Photovoltaic). Una de las técnicas más simples, fáciles y económicas de fabricar películas conteniendo distintas moléculas y polímeros es la de centrifugación. Esta consiste en depositar pequeñas cantidades de la solución líquida sobre un sustrato como vidrio o cuarzo. Esta solución se hace girar a altas velocidades, por ejemplo 2000 rpm, evaporándose rápidamente el disolvente y obteniéndose una película homogénea de gran transparencia y calidad óptica. En base a la centrifugación, se ha desarrollado celdas orgánicas con diversas eficiencias hasta $\operatorname{lograr} 2,2 \%$. En la figura 1 se muestra la evolución de eficiencias logradas. Estas eficiencias se obtuvieron haciendo uso de polímeros semiconductores orgánicos MEH: PPV y P3HT, del fullereno PC61BM y de una molécula de bajo peso molecular basada en boro (M1), que fue sintetizada por investigadores de Universidad de Guanajuato (Barbosa-García). La figura 2 muestra estas estructuras químicas conjuntamente con el compuesto PEDOT: PSS que también juega un papel determinante en la fabricación de las celdas solares orgánicas (homogeneidad y colección de cargas eléctricas en conjunto con el ánodo). Con módulos de celdas ensambladas en serie y en paralelo (figura 3).

Figura 2. Evolución de eficiencias ( $\eta$ ) logradas por (investigadores U de Guanajuato) en celdas solares orgánicas. Curvas típicas de corriente-voltaje, extraído de artículo: file:///C:/Users/Tellez/Downloads/330-Article\%20Text-1864-2-10-20120824.pdf

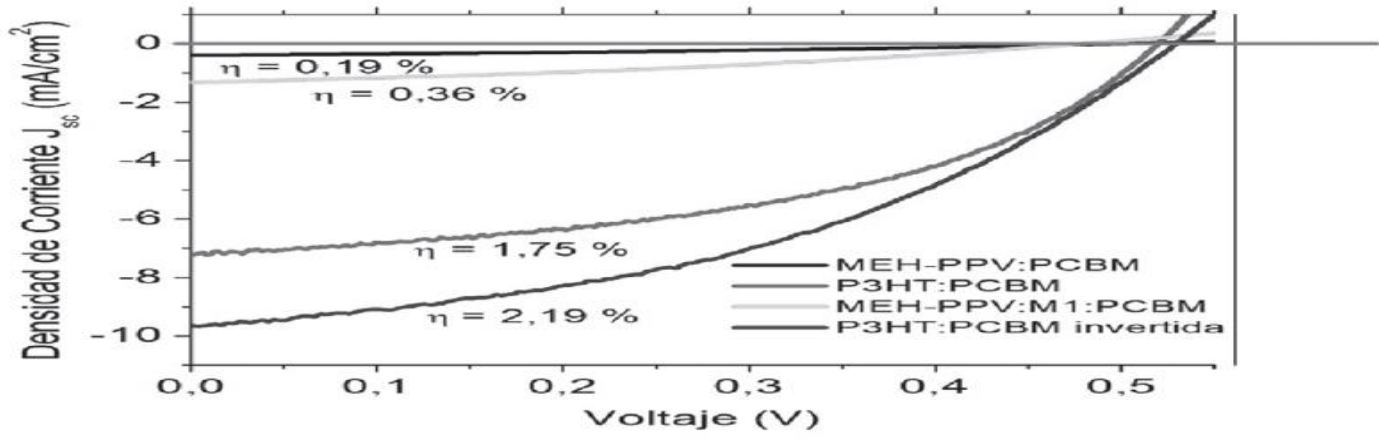


Figura 3. Estructuras químicas de los típicos polímeros MEH:PPV, Fig.3. a) Conexión en serie paralelo para formar módulos fotovoltaicos P3HT y PEDOT:PSS, así como del Fullereno PC61BM usados para de celdas OPVs lo cuales genera aumento de voltaje y corriente la fabricaᄀción de celdas OPVs. Extraído del artículo: file://C:/Users/Tellez/Downloads/330-Article\%20Text-1864-2-10-20120824.pdf
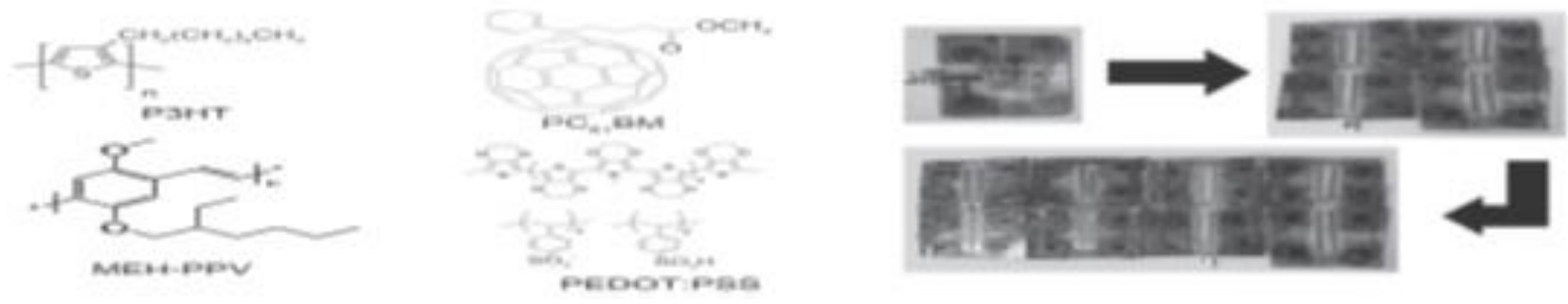

\section{DESCRIPCIÓN DEL MÉTODO}

El proceso para producir electricidad a través de la conversión de fotones se conoce como efecto fotovoltaico (PV), y el dispositivo que ilustra este proceso con materiales orgánicos es la celda OPV.(Organic Photo-Voltaic Cell). Un excitón es una pareja electrón-hueco fuertemente unida por la atracción coulombiana. Por otro lado, cuando una celda OPV se ilumina, la luz es absorbida por el material orgánico y se produce un excitón. El excitón se desplaza entre las moléculas orgánicas ocurriendo una disociación de éste (esto es, la separación de los huecos y electrones), y son los huecos y electrones libres quienes migran a sus respectivos electrodos produciendo un voltaje y una corriente.

En la figura 4, se representa el fenómeno para una celda OPV en su configuración más simple de una sola película orgánica entre dos electrodos (ánodo y cátodo).

Figura 4. a) Esquema más simple para dos dispositivos opto-electrónicos: un OLED y una celda OPV. b) Diseño de una celda solar orgánica (celda OPV) en la arquitectura de heterounión de volumen (BHJ), c) extraído de: https://mercadoelectrico.files.wordpress.com/2012/05/paneles-de-plastico.jpg

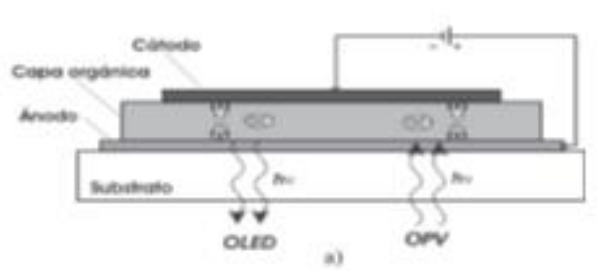

a)

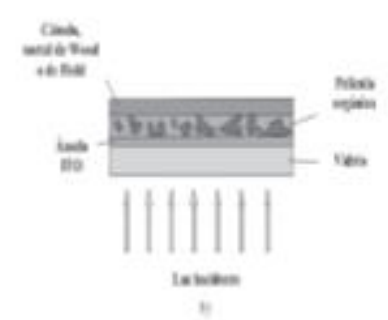

b)

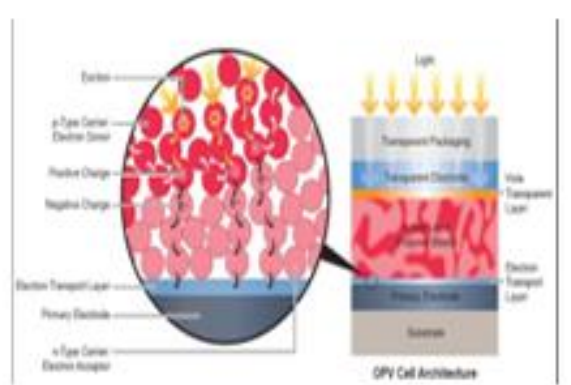

c)

Debido a que la colección de carga para una celda OPV es un factor crucial que determina el voltaje de operación en las celdas OPVs), se usan electrodos metálicos con baja y alta función de trabajo como cátodos y ánodos respectivamente. La función de trabajo es la energía luminosa necesaria para el desprendimiento de un electrón en un metal. Lo anterior mejora la colección de carga en celdas OPVs. La función de trabajo de los electrodos debe además correlacionarse con los niveles energéticos, denominados LUMO (orbital molecular no ocupado más bajo) y HOMO (orbital molecular ocupado más 
alto) de los compuestos orgánicos empleados. Estos niveles LUMO y HOMO son análogos a las bandas de valencia y conducción en un semiconductor inorgánico. También, la movilidad de electrones y huecos (en otras palabras, la rapidez de carga eléctrica por unidad de campo eléctrico aplicado) es otro factor muy importante para el óptimo funcionamiento de las celdas OPVs. En general, los materiales orgánicos transportan preferentemente huecos o electrones con movilidades típicas de entre 10-2 cm2/Vs y 10-9 $\mathrm{cm} 2 / \mathrm{Vs}$.

Dentro de los diversos diseños que se han empleado para incrementar la eficiencia de las OPVs, está el de utilizar capas múltiples de materiales orgánicos. Cada una de estas capas tiene una función específica dentro del dispositivo, por ejemplo, una capa es para inyectar cargas eléctricas, otra es portadora de cargas y otras son emisoras de luz. Las capas activas para las OPVs típicamente son de menos de 100 nm. En la figura 7, la generación de carga eléctrica se asegura a través del volumen entero (heterounión de volumen, BHJ por sus siglas en inglés) de la película foto-activa reduciendo la recombinación de excitones e incrementado la eficiencia de conversión de luz solar.

\subsection{ARQUITECTURA DE UNA CELDA SOLAR ORGÁNICA Y MATERIALES USADOS}

Las primeras investigaciones de una celda solar orgánica datan de 1959, cuando un cristal de antraceno fue estudiado exhibiendo un fotovoltaje relativamente bajo y una muy pobre eficiencia. Hoy en día, las celdas OPVs son dispositivos basados en la combinación de compuestos orgánicos tales como polímeros semiconductores, moléculas de bajo peso molecular y/o algunos derivados de fullerenos (C60). Estos compuestos deben conjuntar dos funciones básicas: a) la fotogeneración de carga eléctrica y b) el transporte de las mismas a través de una unión p-n muy similar a las mostradas por las de origen inorgánico. La combinación de polímeros orgánicos y fullerenos completan la combinación del tipo p-n, donde el polímero rico en electrones y con un gap (diferencia de energías entre los niveles HOMO y LUMO) relativamente pequeño es excitado por la absorción de fotones y transfiere los electrones hacia el otro componente. Los polímeros funcionan como materiales del tipo p -conductores de huecos- y, de forma general, el fullereno tiene el carácter del tipo $\mathrm{n}$-aceptor y conductor de electrones. Las combinaciones de estos materiales dan origen principalmente a dos tipos de arquitecturas las cuales son conocidas como "heterounión de bicapas" y "heterounión de volumen" (BHJ). En la primera, los materiales son depositados en forma de capas secuenciales, una encima de la otra entre los dos electrodos. En la segunda, una mezcla (de volumen) de donador y aceptor es depositada entre los dos electrodos favoreciendo en gran medida el contacto entre estos dos materiales, y con ello la formación de los excitones y fotogeneración de carga. La arquitectura BHJ ha demostrado ser muy conveniente y eficiente. Conjuntamente, se han estudiado un gran número de factores que afectan la función de las celdas solares. Entre estos factores se encuentran la morfología, nuevas arquitecturas de los polímeros, nuevos derivados 
de fullereno, celdas híbridas combinadas con nanopartículas o películas metálicas y capas delgadas con distintas funcionalidades. En la figura 7 (en su parte b), se puede ver esquemáticamente la estructura general de una celda OPV con la arquitectura de heterounión de bulto (versión más simplificada). Recientemente, se ha estimado teóricamente que las eficiencias de conversión de las celdas solares con material orgánico pudieran alcanzar más del $10 \%$ y, con ello, se predice que este tipo de celdas serán de competencia o de complemento con las celdas producidas con base a material inorgánico.

La rapidez de desarrollo de las celdas solares poliméricas está relacionada en buena medida con el diseño y síntesis de nuevos polímeros y moléculas que presenten una fuerte absorción en el intervalo de la radiación visible e infrarroja cercana emitida por el Sol. En la actualidad, se han estudiado una gran cantidad de polímeros conductores de huecos. En forma general se pueden catalogar como a) derivados de estructuras de fenileno/vinileno, b) derivados de tiofenos y, muy recientemente, c) los derivados de fluoreno. De esta manera, con la finalidad de optimizar las celdas solares orgánicas poliméricas, se debe experimentar más en el diseño de nuevos compuestos. Éstos deben ser capaces de fotogenerar cargas eficientemente a partir de la radiación solar y tener una alta conjugación para que puedan transportarlas adecuadamente.

Algunos ejemplos representativos y particulares de polímeros semiconductores donadores de electrones son el poli[2-metóxi-5-(2)etilhexilóxi)-1,4-fenilenovinileno] (o MEH-PPV) que es un derivado de fenil-vinilenos, el poli(3-hexiltiofeno) (o P3HT) que es derivado de cadenas de tiofenos y el poli(9,9'dioctilfluoreno-co-bis-N, N'- (4-butilfenil)-1,4-fenilendiamina) (o PFB) que son derivados de estructuras de fluoreno. El buckminsterfullereno C60 y su derivado altamente soluble éster metílico del ácido fenil C61 butírico (PC61BM) son los típicos representantes de materiales semiconductores aceptores de electrones usados para celdas OPVs (ver figura 3), pero, como ya se mencionó, existe una extensa investigación en diversos polímeros orgánicos. En la figura 3 también se representa el PEDOT:PSS que es un material muy importante en las aplicaciones de electrónica plástica, y que es una mezcla de los polímeros poli(3,4-etilendioxitiofeno) polication (o PEDOT) y poli(stirenosulfonado) polianion (o PSS). Como ya se mencionó, el PEDOT:PSS es un polímero conductor de huecos que se emplea particularmente en las celdas OPVs para mejorar la colección de huecos en el ánodo. Otro importante grupo de moléculas usadas para la fabricación de celdas solares es el de las porfirinas (ver figura 5). Estas unidades se encuentran en las plantas como complejos metálicos de zinc, magnesio, etcétera, y la función de éstas es convertir la luz solar en energía para producir el alimento de tales vegetales. En la figura 5 se observa una porfirina conteniendo un átomo de cobre coordinado (PfCu1) y sintetizada con una serie de anillos de porfirina Pf1-Pf2. 
Figura 5. a) Porfirina conteniendo un átomo de cobre coordinado (PfCu1) sintetizada a partir de una serie de anillos b) de porfirina Pf1-Pf2, c) ejemplo de porfirina de la clorofila por comparación.

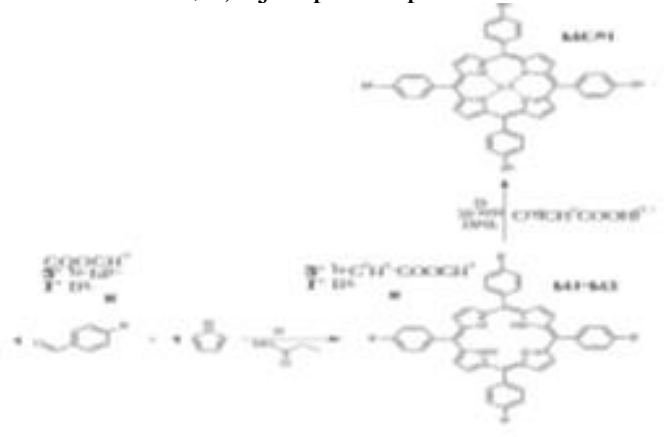

a)

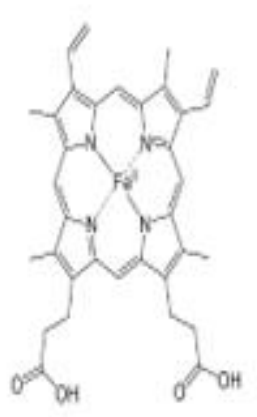

b)

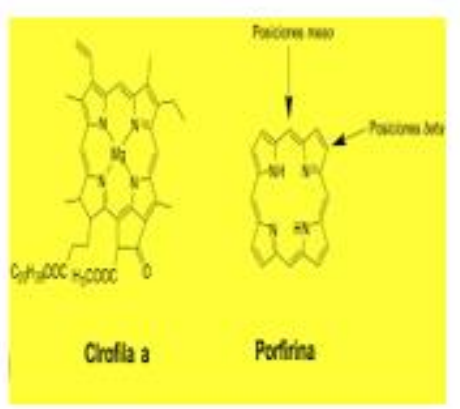

c)

Como se ha mencionado anteriormente, la tecnología de celdas OPVs permite una gran versatilidad en cuanto a materiales usados y diseño de arquitecturas que, entre otras cosas, ha conducido a la aparición de novedosos enfoques en cuanto a la producción masiva de celdas de área grande. Por ejemplo, recientemente una nueva arquitectura invertida de celdas OPVs usando $\mathrm{ZnO}$ como cátodo y PEDOT: PSS, Ag y tintas de plata como ánodo ha posibilitado pruebas de producción roll-to-roll (R2R) a través de procesos donde no se requiere de vacío para su ensamblaje. Estas pruebas de producción masiva con tecnología convencional han alcanzado eficiencias cercanas al $3 \%$ y existe ya una iniciativa llamada "Iluminando África" empleando celdas basadas en polímeros orgánicos. Aunque esta eficiencia no es tan alta como la obtenida con la pareja más convencional de electrodos de óxido de indio/estaño (ITO)-aluminio (Al), sí puede significar una conversión energética y tiempo de vida suficientes para determinadas aplicaciones. Esta singular observación demuestra la flexibilidad que tiene la tecnología basada en materiales orgánicos para generar dispositivos prácticos para, por ejemplo, encender una pequeña lámpara en la oscuridad de la selva o el desierto. De la misma forma, recientemente grupo de investigadores mostró el uso del metal de Wood como otra posibilidad más para la producción en masa usando arquitecturas no convencionales. El metal de Wood es una mezcla de 4 metales: plomo, bismuto, cadmio y estaño que se funde a solo $75^{\circ} \mathrm{C}$ y que permite una fácil deposición del cátodo sin necesidad de un sistema de evaporación al vacío. En la figura 6 se observa la deposición de las películas orgánicas por centrifugación en un sustrato de vidrio ya con el ánodo (ITO), el depósito del metal de Wood (cátodo) y pruebas de laboratorio para ver el funcionamiento eléctrico de la celda OPV fabricada. 
Figura 6. Proceso de manufactura: deposición de películas orgánicas por centrifugación en un sustrato de vidrio con el ánodo (ITO), depósito del metal de Wood y observación de la función fotovoltaica de una celda solar orgánica. El metal de Wood pudiera ser una alternativa a los electrodos tradicionales usados.

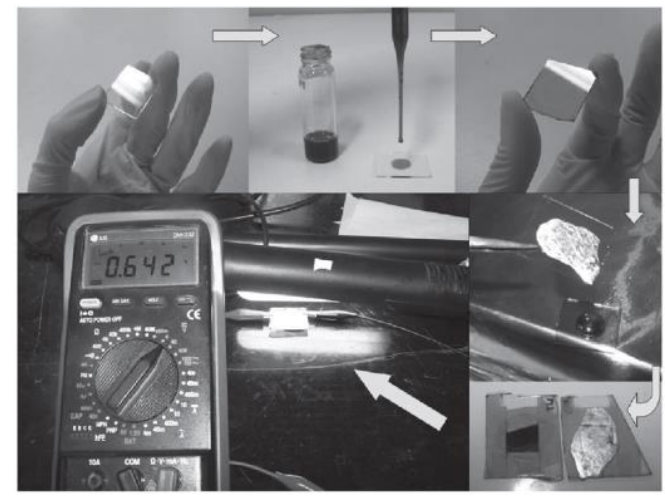

\subsection{PREPARACIÓN DE LAS CELDAS OPVS}

Las películas orgánicas son preparadas por los métodos tradicionales (como la centrifugación) usando distintos disolventes y empleando diferentes concentraciones de moléculas y polímeros a mezclar. Se depositan sobre sustratos de vidrio o plástico conteniendo ITO, que usualmente es el ánodo. Estos electrodos de ITO deben de estar completamente limpios. Para ello, son lavados usando ultrasonido y baños de etanol, agua y soluciones para limpieza de sustratos, ya que cualquier partícula de polvo o humedad puede afectar considerablemente la calidad de las películas y, con ello, la funcionalidad de las celdas solares. Para el cátodo se puede usar el metal de Wood que se vierte en un matraz de vidrio Pyrex sobre una parrilla por encima de $\operatorname{los} 90^{\circ} \mathrm{C}$ y, subsecuentemente, se vierte sobre las películas orgánicas previamente depositadas. En la ya mencionada y descrita figura 6

\subsection{CARACTERIZACIÓN ELÉCTRICA-ÓPTICA DE CELDAS OPVS}

La caracterización eléctrica-óptica de una celda solar se realiza al medir la eficiencia de conversión (ๆ) bajo la condición de iluminación AM 1.5 (estándar de intensidad de iluminación sobre la superficie de la Tierra cuando el ángulo cenit del Sol es de $48^{\circ}$ y corresponde entre $800 \mathrm{~W} / \mathrm{m} 2$ y $1000 \mathrm{~W} / \mathrm{m} 2$ ). Los parámetros útiles para lo anterior son (ver figura 7): el voltaje de circuito abierto (Voc), la densidad de corriente de corto circuito (Jsc), el máximo voltaje de potencia (Vm), la máxima densidad de corriente de potencia (Jm) y el factor de llenado (FF). Este factor y la eficiencia están definidos por las ecuaciones (1) y (2), donde Pin es la intensidad de iluminación incidente. Para lograr altas eficiencias de conversión eléctrica se requiere tener los máximos valores de Voc, Jsc, y FF.

$$
\begin{aligned}
& \eta=F F \frac{V_{o c} J_{s c}}{P_{\text {in }}} \\
& F F=\frac{V_{m} J_{m}}{V_{o c} J_{s c}}=\frac{P_{\max }}{V_{o c} J_{s c}}
\end{aligned}
$$


Las celdas son preliminarmente probadas bajo iluminación solar y, posteriormente, se obtienen las curvas J-V (ver también figura 2) determinando las eficiencias con un medidor-fuente de corriente-voltaje y una lámpara de xenón calibrada con una celda solar de referencia a $100 \mathrm{~mW} / \mathrm{cm} 2$. La lámpara de xenón emite luz con un espectro muy similar al del sol en el visible y cercano infrarrojo. Las pruebas se realizan en condiciones atmosféricas (pudiéndose también realizar bajo atmósferas controladas). Como se menciona en las referencias y, con algunas de nuestras moléculas en combinación con polímeros comerciales, así como con el uso del metal de Wood en uno de los electrodos, el GPOM ha logrado Voc $~ 700 \mathrm{mV}$, Jsc $\sim 7,5 \mathrm{~mA} / \mathrm{cm} 2$ у $\eta \sim 1,8 \%$, aunque muy recientemente ya se obtuvo $\eta \sim 2,2$ (ver figura 2 ).

Figura 7. a) Gráfica J-V para una celda OPV típica. Geométricamente, el factor de llenado (FF) puede visualizarse como la razón de áreas del rectángulo gris y el rectángulo punteado (Pmax/VocJsc). b) Fotografías de celdas solares con el metal de Wood como cátodo, en contraposición con una inorgánica en paralelo cuya J-V no aparece pero es aun 10 menor con respecto a los resultados.

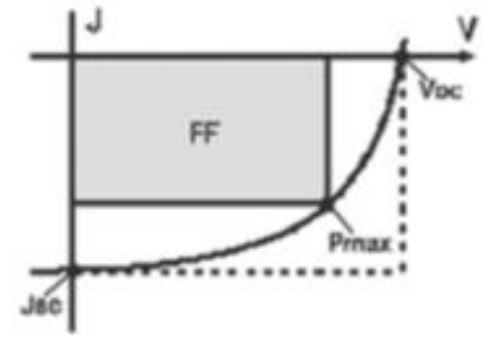

a)

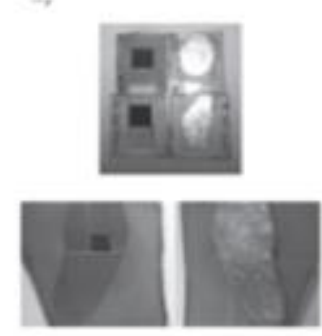

b)

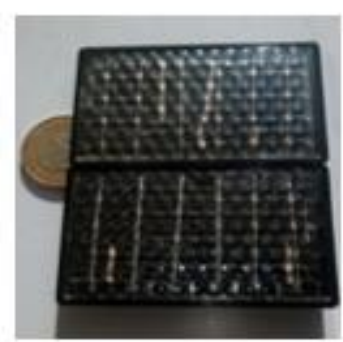

c)

\section{COMENTARIOS FINALES}

Este estudio se ha presentado un panorama actual y general del desarrollo de las celdas solares basadas en materiales orgánicos. Este tipo de bioceldas generan energía eléctrica y, conjuntamente con otras fuentes de energía renovables, serán las fuentes de energía del futuro. Para sustituir las fuentes de energía no renovables, se tendrá que recurrir a diversas tecnologías que satisfagan nuestras necesidades actuales de consumo energético.

\section{RESUMEN DE RESULTADOS}

En este trabajo investigativo se estudió las celdas OPVs pertenecen a una de esas tecnologías y actualmente buscan complementar y/o sustituir en lo posible el uso de la tecnología basada en materiales inorgánicos. Entre las ventajas de las celdas OPVs, se tiene el costo menor en la producción de energía, ya que no se requiere de laboratorios sofisticados, de alto costo y de mantenimiento elevado; asimismo, se cuenta con la ventaja de generar menor cantidad de contaminantes durante su producción. Para un mayor éxito de las celdas OPVs, es necesario, aparte de la búsqueda de una mayor eficiencia de 
conversión, incrementar su tiempo de vida y tener una tecnología adecuada para el almacenamiento de la energía eléctrica producida.

\section{CONCLUSIONES}

Por los estudios elaborados hasta aquí comprendemos lo emocionante que nos genera expectativas de aumentar la eficiencia de generación de energía de conversión, incrementar su tiempo de vida y tener una tecnología adecuada para el almacenamiento de la energía eléctrica producida. Estudiar nanotecnología en la búsqueda de resultados favorables y a la vez casi reciente descubrimientos con materiales orgánicos, nos resta decir que son significativos los resultados de tan bajas eficiencias pero no dudar de la posibilidad ilimitada en los logros reportados (Samsun reporto 20\%) de obtención de bioelectrcidad, esto abre posibilidades de un día cambiar los sistemas inorgánicos por los orgánicos ventajas serán conjuntamente con otras fuentes de energía renovables, serán las fuentes de energía del futuro y así asegurar descontaminación de nuestro planeta.

\section{RECOMENDACIONES}

Los investigadores en continuar este estudio necesitan enfocarse para lograr el incremento en una mayor eficiencia, realizar más investigación en tres líneas:

a) Síntesis de nuevos materiales orgánicos capaces de absorber la mayor cantidad de luz solar sobre todo en la región visible y cercano infrarrojo.

b) Aumento de la eficiencia ( $\boldsymbol{\eta}$ ), combinando diferentes materiales con nuevas arquitecturas

c) Comprensión fundamental de los fenómenos físico-químicos involucrados (estudios espectroscópicos) 


\section{REFERENCIAS}

Barbosa-García O, y J.L. Maldonado. "Celdas solares orgánicas como fuente de energía sustentable," Revista Acta Universitaria, Vol. 22, No. 5, 2012, Universidad de Guanajuato, consultada por Internet el 1 de junio del 2019. Dirección de internet:

Colonna Paul. "La química Verde," Instituto Nacional de la recherche agronomique” Ed. ACRIBIA S.A. Julio del 2016.

Washington. W. y F. Frank" Paneles solares Biológicos" liga internet: http://omicrono.elespanol.com/2016/04/paneles-solares-bologicos

Saavedra Salas I. "Diseño de una celda de combustible microbiológica con uso de bacterias oxidantes de azufre y hierro," tesis de Ing. Civil Químico, liga de internet PDF.

\section{NOTAS BIOGRÁFICAS}

El M.C. Rubén Tellez Hernández, Este autor es profesor Ing. Industrial de la Universidad Tecnológica de Tecamachalco, Puebla, México. Terminó sus estudios de postgrado en Instituto Universitario Puebla (IUP), Puebla, Pué. Ha publicado artículos en CICA cuerpos académicos UTSOE y dirige proyectos, con su equipo de trabajo".

La Ing. Yadira Varillas Gonzales es profesora de la U. Tecnológica de Tecamachalco, Puebla. Responsable en Ingeniería Industrial en Logística e IO. Yadira proporciona servicios de consultoría en el área de Calidad y Logística y ha trabajado como ing. De planta área manufactura automotriz y logística.

El Dr. Jorge A. es coordinador de cuerpos académicos carrera de Ing. Industrial Universidad T. de Tecamachalco, Puebla, México. El Dr. tiene maestría y doctorado en Mecatronica de la Universidad Popular Autónoma de Puebla (UPAEP), Puebla, México.

El MC. Fermín Tenorio Cruz es profesor de Ing. Mecatronica en la Universidad T. de Tecamachalco. Ha dirigido 16 proyectos de robótica y Drones. Sus artículos han aparecido en revistas como CICA 2018 y 2019 y concursos de $1^{\circ}$ lugar en diversos eventos de ciencia robótica. Sus servicios de consultoría son en las áreas de Robótica, Control Avanzado, y Física. 